\title{
Guest Encapsulation Within Surface-Adsorbed Self-Assembled Cages
}

Hugh P. Ryan, Dr. Cally J. E. Haynes, Alyssa Smith, Dr. Angela B. Grommet, Prof. Jonathan R. Nitschke*

University of Cambridge, Department of Chemistry, Lensfield Road, Cambridge, UK, CB2 $1 \mathrm{EW}$

\section{E-mail: jrn34@cam.ac.uk}

Keywords: coordination cages, adsorption, self-assembly, supramolecular chemistry

Coordination cages encapsulate a wide variety of guests in the solution state. This ability renders them useful for applications such as catalysis and the sequestration of precious materials. A simple and general method for the immobilization of coordination cages on alumina is reported. Cage loadings are quantified via adsorption isotherms and guest displacement assays demonstrate that the adsorbed cages retain the ability to encapsulate and separate guest and non-guest molecules. Finally, a system of two cages, adsorbed on to different regions of alumina, stabilizes and separates a pair of Diels-Alder reagents. The addition of a single competitive guest results in the controlled release of the reagents, thus triggering their reaction. We envisage this method of coordination cage immobilization on solid phases to be applicable to the extensive library of reported cages, enabling new applications based upon selective solid-phase molecular encapsulation.

The assembly of discrete supramolecular hosts and their solution-phase behavior have been well-studied. ${ }^{[1-17]}$ Such species adopt a variety of geometries and have found uses in the encapsulation and separation of valuable and hazardous materials, ${ }^{[18-21]}$ moving cargoes between immiscible phases, ${ }^{[22,23]}$ and catalysis. ${ }^{[24-31]}$

The translation of solution-state chemistry on to solid supports has revolutionized the preparation of peptides and nucleotides, resulting in increased synthetic simplicity, speed, and 
efficiency. ${ }^{[32,33]}$ The incorporation of platinum(II) complexes into mesoporous silica has been shown to stabilize and enhance the photophysical properties of emissive complex aggregates and electrochromic devices have been formed from polypyridyl mononuclear metal-organic complexes on glass and polyethylene terephthalate. ${ }^{[34-37]}$ Furthermore, systems of adsorbed organic macrocycles have been utilized in more biologically-relevant contexts. For example, cucurbit[7]uril immobilized on Sepharose resin has been shown to recognize insulin and human growth hormone from complex protein mixtures, ${ }^{[38]}$ and tetralactam macrocycles and polycationic pillar[5]arene on ion exchange resins have shown great promise in detecting enzymatic cleavage activity and in the removal of toxic organic species from aqueous media, ${ }^{[39-41]}$ respectively. The immobilization of coordination cages on solid supports provides an opportunity to carry out applications that require heterogeneous encapsulation, thus avoiding the need for subsequent host-guest separation steps, without modification of the cage frameworks. Furthermore, cage immobilization enables cages and their cargoes to be spatially separated, which cannot be achieved in homogeneous solution. Self-assembled monolayers have been used to covalently tether cavitand-based structures to surfaces such as silica and gold and recent work has shown that chromatographic silica can be covalently functionalized with supramolecular host species. ${ }^{[42-46]}$ Scanning tunneling microscopy (STM) has been used to study the organization of $2 \mathrm{D}$ and 3D nanoarchitectures on surfaces, and surface-enhanced Raman spectroscopy (SERS) has been employed to demonstrate the structural integrity of platinum-based coordination cages on a nanostructured gold surface. ${ }^{[47,48]}$ The field of surface-bound molecular containers is thus ripe for the development of new applications.

Coordination cage adsorption provides a simple route to cage immobilization on solid supports, in comparison to the more involved process of covalent surface tethering. ${ }^{[2-45]}$ Here we characterize the straightforward adsorptive fixation of two tetrahedral coordination capsules, each formed via subcomponent self-assembly, on to activated alumina from aqueous 
a
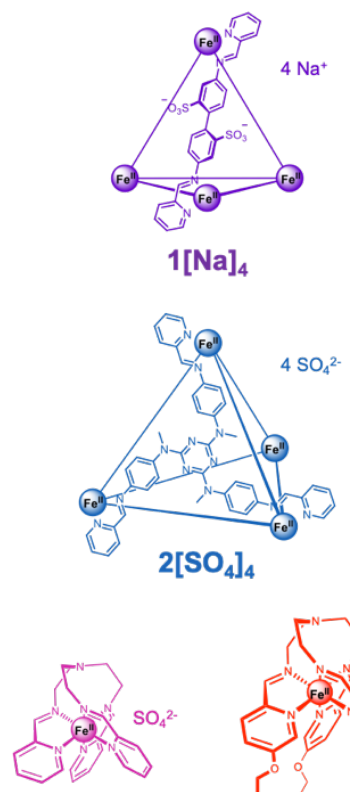

$3\left[\mathrm{SO}_{4}\right]$

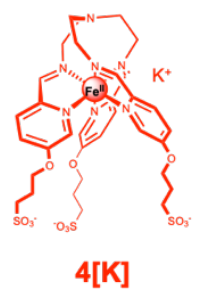

b

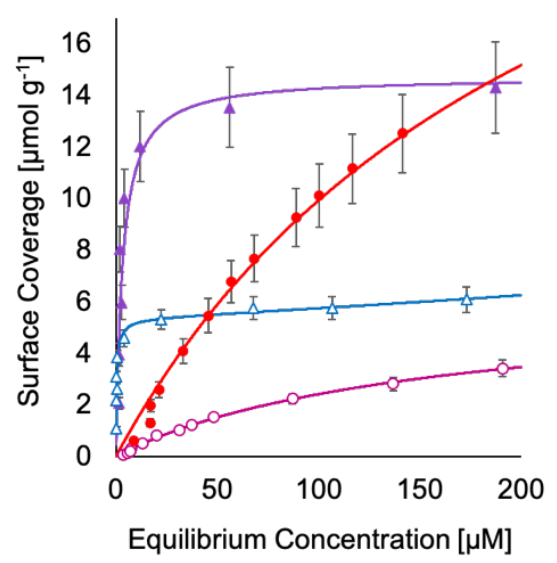

$\bigotimes_{\text {acidic alumina }}^{1 \text { on }}$

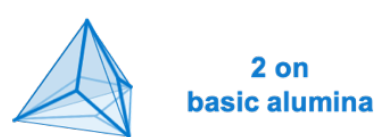

₹ 3 on

basic alumina

$\mathbb{R} \quad 4$ on

acidic alumina c

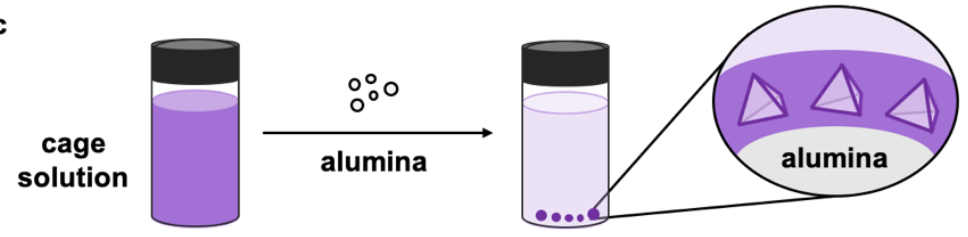

Figure 1. Structures and adsorption isotherms of complexes 1-4 on alumina. a, Structures of

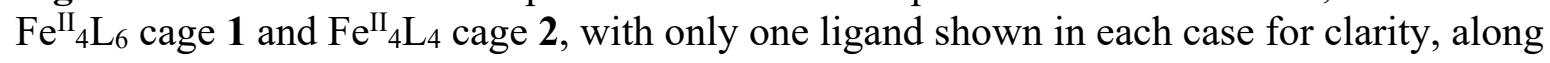
with mononuclear complexes 3 and $\mathbf{4}$. b. Isotherms describing the adsorption of species 1-4 on to alumina from aqueous solutions. c, Schematic showing the adsorption of these complexes on to alumina from solution.

solution. We demonstrate that these species remain both intact and functional following adsorption - the adsorbed cages retain their ability to bind and release guest molecules.

Finally, we utilize the host-guest chemistry of a system of two adsorbed cages to spatially separate the components of a Diels-Alder reaction; these components are then controllably released following the addition of a competitive guest, leading to their reaction.

The adsorption isotherms of anionic coordination cage $\mathbf{1}$ and cationic coordination cage $\mathbf{2}$

(Figure 1) on acidic and basic alumina, respectively, were determined using the solution depletion method (see Figure 1c and Supplementary Information section S5). We attribute these adsorption behaviors to electrostatic interactions; anionic cage $\mathbf{1}$ adsorbs preferentially on to the positively charged surface characteristic of an acidic support, whereas cationic cage $\mathbf{2}$ is conversely attracted to the negative charges associated with a basic support. We observed 
minimal adsorption of cage $\mathbf{1}$ on to basic alumina and cage $\mathbf{2}$ on acidic alumina. The adsorption isotherms of cationic mononuclear complex $\mathbf{3}$ on basic alumina and novel, anionic mononuclear complex $\mathbf{4}$ on acidic alumina were also collected; complexes $\mathbf{3}$ and $\mathbf{4}$ were used throughout as a control coordination species with no cage cavities. Species 1-3 were prepared following literature procedures. ${ }^{[49-51]}$ The isotherms were fitted using a solution analogue of the Brunauer-Emmett-Teller (BET) model isotherm over the range $0-200 \mu \mathrm{M} \cdot{ }^{[52]}$ Monolayer surface coverages $\left(\theta_{\mathrm{MONO}}\right)$ of $15(1) \mu \mathrm{mol} \mathrm{g}^{-1}, 5.3(4) \mu \mathrm{mol} \mathrm{g}^{-1}, 5.5(2) \mu \mathrm{mol} \mathrm{g} \mathrm{g}^{-1}$, and 30(2) $\mu \mathrm{mol}$ $\mathrm{g}^{-1}$ were calculated for species $\mathbf{1}, \mathbf{2}, \mathbf{3}$, and $\mathbf{4}$, respectively. The adsorbate-surface binding constants $\left(K_{\mathrm{S}}\right)$ of $3(1) \times 10^{5}, 2.3(7) \times 10^{6}, 7.4(4) \times 10^{3} \mathrm{M}^{-1}$, and $4.8(4) \times 10^{3} \mathrm{M}^{-1}$ for $\mathbf{1}, \mathbf{2}, \mathbf{3}$, and 4 correspond to free energies of adsorption of approximately $-31(1) \mathrm{kJ} \mathrm{mol}^{-1},-36.3(7) \mathrm{kJ}$ $\mathrm{mol}^{-1},-22.1(1) \mathrm{kJ} \mathrm{mol}^{-1}$, and $-21.0(2) \mathrm{kJ} \mathrm{mol}^{-1}$. We hypothesize that the lower values of $K_{\mathrm{S}}$ for species $\mathbf{3}$ and $\mathbf{4}$, relative to those for cages $\mathbf{1}$ and $\mathbf{2}$, result from a lower net charge density of these mononuclear complexes. Furthermore, we hypothesize that the larger net charge of density of cage $\mathbf{2}$, relative to that of cage $\mathbf{1}$, results in its larger value of $K_{\mathrm{S}}$. Furthermore, we hypothesize that the larger net charge of density of cage $\mathbf{2}$, relative to that of cage $\mathbf{1}$, results in its larger value of $K_{\mathrm{S}}$. The adsorbate-adsorbate binding constants $\left(K_{\mathrm{L}}\right)$ of $c a .10^{2} \mathrm{M}^{-1}$ for species $\mathbf{2}$ and $\mathbf{3}$ suggest the gradual formation of electrostatic multilayers of cations and anions at the alumina surface as the concentrations of $\mathbf{2}$ and $\mathbf{3}$ increased in solution. In contrast, the $K_{\mathrm{L}}$ value of $\sim 0$ for $\mathbf{1}$ on acidic alumina suggests the formation of only a monolayer of cages; we hypothesize that the sodium counter-cations of $\mathbf{1}$ may be too well hydrated to support the formation of electrostatic multilayers. Similarly, we hypothesize that the hydrated potassium counter-cations of 4 result in its low value of $K_{\mathrm{L}}\left(c a \cdot 10^{1} \mathrm{M}^{-1}\right)$. Cage 1 was observed to desorb intact from the surface of acidic alumina at $\mathrm{pD} 9-10$, following the suspension of the adsorbed cage on alumina in aqueous $\mathrm{NaOH}(c a .10 \mathrm{mM}$, see Section S13.1, Figure S75), thereby supporting the intact adsorption of cage 1 on acidic alumina. Conversely, 
cage 2 desorbed intact from basic alumina at pD 4-5 upon suspension in aqueous $\mathrm{HCl}$ (ca. 1 $\mathrm{mM}$, Figure S76).

The kinetics of adsorption of cage $\mathbf{1}$ on acidic alumina (Figure S14) were also investigated by varying the equilibration time for a series of samples with the same initial conditions. After 5 minutes of equilibration, the surface coverage had reached more than $95 \%$ of its final value. The data were fitted well using the second-order model of adsorption kinetics developed by Blanchard et al., with parameters of $\theta_{\mathrm{MAX}}$ and $k$ (equilibrium coverage and rate constant) determined to be $13.97(3) \mu \mathrm{mol} \mathrm{g}{ }^{-1}$ and $0.0081(2)\left(\mu \mathrm{mol} \mathrm{g}^{-1}\right)^{-1} \mathrm{~s}^{-1}$, respectively. ${ }^{[53]}$

Following the adsorption of $\mathbf{1} \mathbf{- 4}$ on to alumina, these species were investigated spectroscopically and through guest displacement experiments.

The optical transmission spectra of $\mathbf{1}$ and $\mathbf{4}$ adsorbed on acidic alumina, as well as $\mathbf{2}$ and $\mathbf{3}$ adsorbed on basic alumina, (Figure S15-18) showed retention of the metal-to-ligand chargetransfer (MLCT) bands seen in solution (500-600 nm, Figure S2, S4, S6, S8). The solutionphase local maxima at $572 \mathrm{~nm}$ and $571 \mathrm{~nm}$ for cages $\mathbf{1}$ and $\mathbf{2}$ were observed as minima in the transmission spectra, at $585 \mathrm{~nm}$ and $579 \mathrm{~nm}$ respectively (Figure S15, S16). Similarly, the solution-phase MLCT maxima at $559 \mathrm{~nm}$ and $536 \mathrm{~nm}$ of complexes 3 and $\mathbf{4}$ were observed as minima at $566 \mathrm{~nm}$ and $542 \mathrm{~nm}$ in their transmission spectra, respectively (Figure S17, S18).

X-ray Photoemission Spectroscopy (XPS) following the adsorption of cage $\mathbf{1}$ on acidic alumina showed a Fe2p band at a binding energy of 710-730 eV (Figure S19). Quantification of XPS results indicated that iron atoms accounted for $0.2 \%$ of the atoms in the surface layers. 

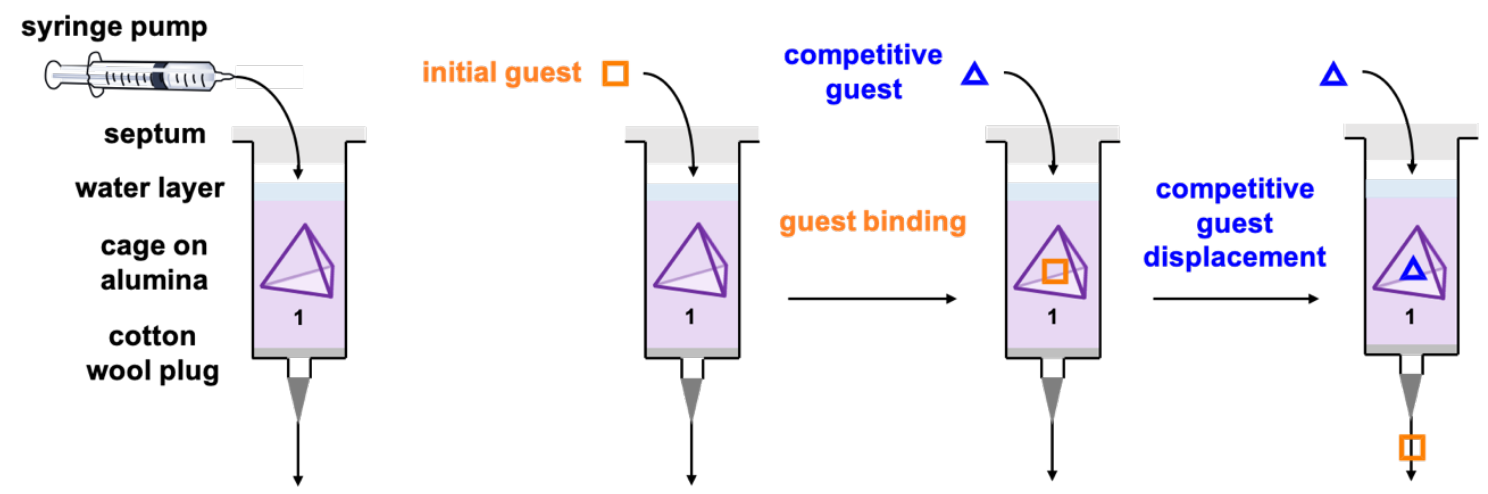

Figure 2. Guest loading and displacement setup. a, Schematic showing the flow setup utilized to bind guest molecules within adsorbed cage 1. b, Schematic showing a general case of the initial binding of one guest (orange square) and subsequent displacement by a competitive guest (blue triangle). An analogous method was used for adsorbed cage 2. In systems of chemical separation the initial guest may be taken to include a mixture of guest and non-guest species.

This value is consistent with the surface coverage determined by analysis of the adsorption isotherm (see Supplementary Information Section S8.3 for full details). No Fe2p band was observed for the bare acidic alumina substrate (Figure S20). Additionally, EDX spectroscopy confirmed the presence of iron on the alumina surfaces following the adsorption of species $\mathbf{1}$, 2, and 4 (Figure S21, S22, S24). The iron signal was not distinguishable from the noise for species 3 on basic alumina (Figure S23); we attribute this observation to the low surface coverage of species $\mathbf{3}$ on alumina and its lower iron content ( 1 atom per complex) relative to that of cages 1 and $\mathbf{2}$ (4 atoms per complex). No iron signals were observed for the bare acidic and basic aluminas (Figure S25, S26).

Previous work has shown that cages $\mathbf{1}$ and $\mathbf{2}$ bind many organic guests in water. ${ }^{[49,54]}$ In order to establish the persistence of the cage cavities following adsorption, guest displacement experiments were performed using columns containing cages $\mathbf{1}$ and $\mathbf{2}$ adsorbed on alumina. Guest displacement experiments were performed using the flow setup shown in Figure 2. An aqueous solution of an initial guest was eluted through a column containing either cage $\mathbf{1}$ or 


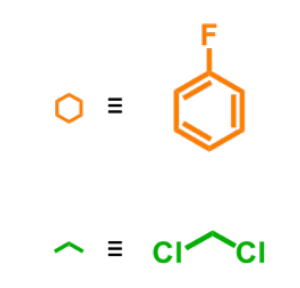

a

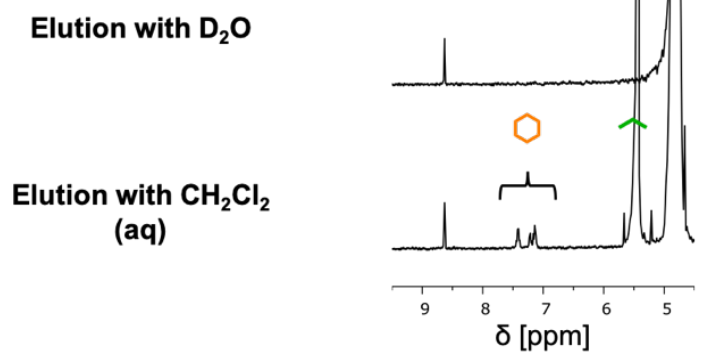

b
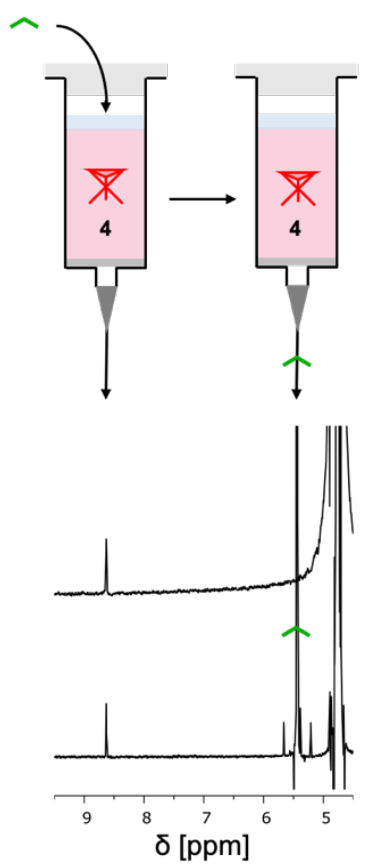

c
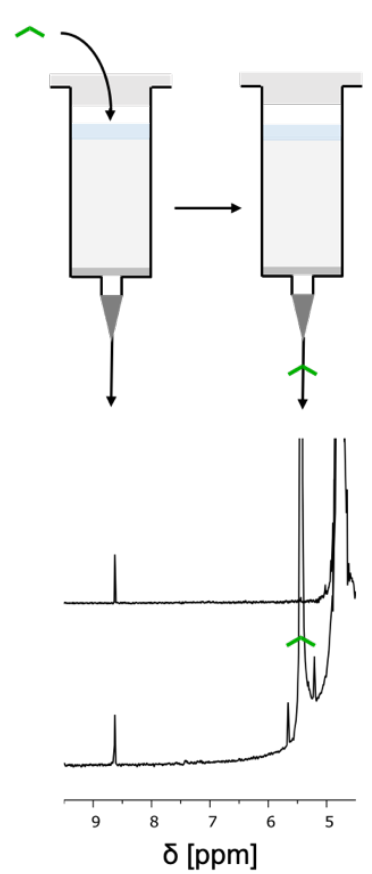

Figure 3. Displacement of fluorobenzene from adsorbed cage 1. a, Schematic and ${ }^{1} \mathrm{H}$ NMR spectra of displacement of fluorobenzene from within adsorbed $\mathbf{1}$ by dichloromethane. $\mathbf{b}$, Schematic and ${ }^{1} \mathrm{H}$ NMR spectra of control experiment with adsorbed 4. c, Schematic and ${ }^{1} \mathrm{H}$ NMR spectra of control experiment with bare acidic alumina. Thus the retention and subsequent release of fluorobenzene was only observed in $\mathbf{a}$, in which persistent cage cavities were present. The peak at $8.63 \mathrm{ppm}$ throughout corresponds to pyrazine at $2 \mathrm{mM}$.

cage 2 loaded on to alumina. The column was then washed with water to remove excess guest. Subsequently, $1 \mathrm{~mL}$ aliquots of an aqueous solution of a second, competitive guest were eluted through the cage column and the eluates were analyzed by ${ }^{1} \mathrm{H}$ NMR (see Supplementary Information Section S10 for full details). Fluorobenzene (solution $K_{\mathrm{a}}=610 \mathrm{M}^{-}$ ${ }^{1}$ for $\left.\mathbf{1}\right)$ was thus passed through a column of $\mathbf{1}$ adsorbed on to acidic alumina, followed by a water wash, as described in Supplementary Section S10.1. Following elution with aqueous dichloromethane (saturated, $c a .0 .2 \mathrm{M}$, solution $K_{\mathrm{a}}=1300 \mathrm{M}^{-1}$ for $\mathbf{1}$ ), we observed the release of fluorobenzene at millimolar concentration (Figure 3). ${ }^{[54,55]}$ Control experiments were run identically but using complex $\mathbf{4}$ adsorbed on acidic alumina and bare acidic alumina in place of $\mathbf{1}$ on acidic alumina. These controls gave no evidence of the retention or release of fluorobenzene. We thus infer the guest release observed (Figure 3) to result from the persistence of the cavity of cage $\mathbf{1}$ following adsorption. In identical fashion, fluorobenzene 
was displaced from cage $\mathbf{2}$ adsorbed on basic alumina upon elution with aqueous dichloromethane (Figure S58), thereby demonstrating the persistence of its cavity. We hypothesize that the use of different metal vertices could tune this guest retention and release; for example, the increased lability of the cobalt(II) coordination sphere, relative to that of iron(II), might result in faster guest release from cages with cobalt(II) vertices. Control experiments with complex $\mathbf{3}$ adsorbed on basic alumina and bare basic alumina showed no retention and release of fluorobenzene. In contrast, when solutions of three water-soluble nonguest molecules, phloroglucinol, pentaerythritol, and trifluorobenzene were run through columns of 1 adsorbed on acidic alumina (Figure S38-40, S54-56), no subsequent retention and release of these molecules was observed. A column of $\mathbf{1}$ adsorbed on acidic alumina was then used to separate to fluorobenzene from trifluorobenzene. The aqueous guest mixture was eluted through the cage column, and subsequent elution with aqueous dichloromethane resulted in the release of fluorobenzene (Figure S68-70). This chemical separation qualitatively demonstrates the potential of adsorbed coordination cages to achieve the separation of chemically similar compounds. As the library of known cages continues to expand, future systems of adsorbed cages will be able to achieve more chemically significant separations based on the binding affinities of individual cages. Finally, we investigated the reusability of a column of $\mathbf{1}$ on acidic alumina and observed that the column could be recycled, i.e. fluorobenzene could be loaded and then released from the adsorbed cages, for at least 3 cycles (Figure S57).

Solution-phase ${ }^{1} \mathrm{H}$ NMR studies indicated that cage $\mathbf{1}$ bound cyclopentadiene in water with a binding affinity of $1.4 \times 10^{3} \mathrm{M}^{-1}$ (Figure S46) and cage 2 bound N-propyl maleimide in water with a binding affinity of $1.5 \times 10^{3} \mathrm{M}^{-1}$ (Figure S49). We thus set out to design a system 
a

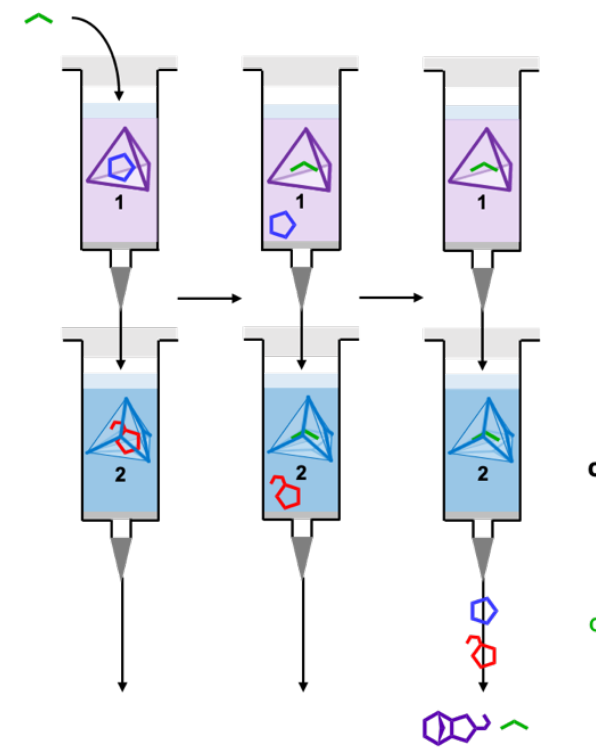

b
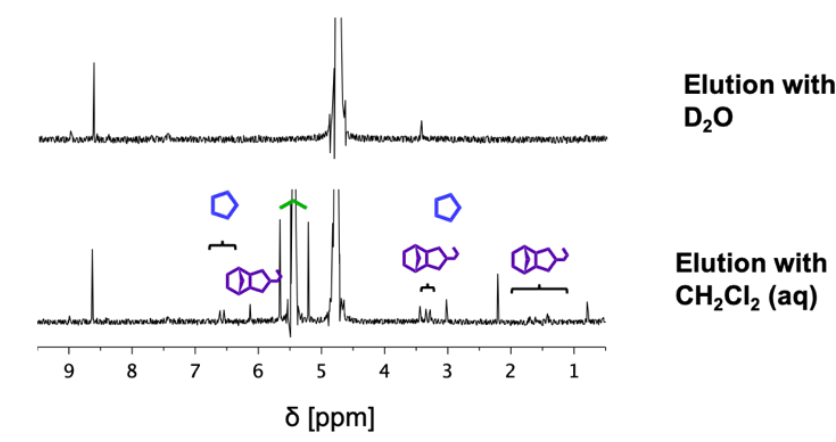

Elution with $\mathrm{CH}_{2} \mathrm{Cl}_{2}$ (aq)

Figure 4. Compartmentalization of Diels-Alder components within adsorbed cages 1 and 2. a, Schematic of the sequential loading and displacement in series of cyclopentadiene (blue pentagon) and N-propyl maleimide (red pentagon with tail) from adsorbed $\mathbf{1}$ and $\mathbf{2}$ to trigger a Diels-Alder reaction, the product (purple) of which eluted. $\mathbf{b},{ }^{1} \mathrm{H}$ NMR spectra of the elution of the system with $\mathrm{D}_{2} \mathrm{O}$ and aqueous dichloromethane, shown in part a. c, The overall guest displacement and subsequent Diels-Alder adduct.

capable of storing this reactive diene and dienophile within distinct regions of a column and modulating their reactivity in a potentially useful way. The flow setup described above was used to store and release cyclopentadiene using a column of 1 (Figure S52) and N-propyl maleimide using a column of 2 (Figure S59). Although cyclopentadiene is known to dimerize on the timescale of hours at room temperature, the cyclopentadiene stored within immobilized 1 was released intact after a storage period of two weeks (Figure S53), thereby demonstrating the ability of $\mathbf{1}$ to modulate the reactivity of this otherwise-unstable species. Columns connected in series of cage $\mathbf{1}$ loaded with cyclopentadiene and cage $\mathbf{2}$ loaded with N-propyl maleimide (Figure 4) thus enabled the Diels-Alder partners to be separated and stabilized, while allowing the reaction to be turned on through elution of the two-column system with aqueous dichloromethane. Columns of $\mathbf{1}$ and $\mathbf{2}$ were loaded with cyclopentadiene and Npropyl maleimide, respectively, as shown in Figure 2. Following the addition of $1 \mathrm{~mL}$ aliquots 
of aqueous dichloromethane, the eluate of the series of columns was analyzed by ${ }^{1} \mathrm{H}$ NMR, which showed the presence of the Diels-Alder product shown in Figure 4c. This compartmentalization of reagents could be achieved by loading guests into the cage columns either separately (Figure 4, S73) or in series (Figure S74), i.e. from a single input line. Systems of cages adsorbed on alumina can thus be used to store reagents, inhibiting an unwanted reaction (cyclopentadiene dimerization), as well as to trigger a desired reaction by liberating both Diels-Alder partners through the addition of a single stimulus molecule. We anticipate that this modulation of chemical reactivity could find future application in facilitating reactions in which two or more reactive components require stabilization prior to the initiation of their reaction.

Oppositely-charged cages $\mathbf{1}$ and $\mathbf{2}$ were observed to bind strongly to alumina supports, with retention of the binding abilities that they exhibit in solution. The present study thus paves the way for the immobilization of many of the other cages that have been reported to date. ${ }^{[1,4,5]}$ Future studies will investigate the quantification of the host-guest chemistry of adsorbed coordination cages and the immobilization of cages capable of binding more complex and information-rich guests. Such supported cages might be employed within fluidic networks, to capture and release specific guest compounds and thus to engineer reactions between specific reagents. The ability to trap and release compounds with high selectivity from mixtures flowing over solid supports may enable new methods of chemical purifications, for example in the purification of larger and more information-rich molecules, such as drugs. ${ }^{[56]}$ The immobilization of cages might also enable the translation of these versatile homogeneous catalysts into heterogeneous catalysts.. ${ }^{[4,24-31]}$ 


\section{Experimental Section}

\section{Adsorption Isotherms}

The adsorption isotherms were collected via the solution depletion method. Known masses of adsorbent (200 mg) were added to a series of cage/complex solutions of known concentrations $(0-4 \mathrm{mM})$ and volumes $(2 \mathrm{~mL})$. The samples were equilibrated via tumbling for 10 minutes at 40 RPM and then centrifuged for 2 minutes at 3000 RPM. The concentrations of the supernatant solutions were then determined using UV-vis calibration curves. The depletion of material from solution was attributed to adsorption on the solid support.

\section{Guest Displacement Experiments}

Solid alumina support $(1 \mathrm{~g})$ was added to solution of excess cage/complex in water $(10 \mathrm{~mL})$ and stirred to adsorb the material. The alumina slurry was then loaded into a $5 \mathrm{~mL}$ syringe, which contained a cotton wool plug to prevent the alumina from passing through the syringe. The "cage column" was washed with water to remove the excess cage/complex. An initial guest solution was eluted slowly through the column $(3 \mathrm{~mL}, 0.1 \mathrm{~mL} / \mathrm{min})$ and the column was washed with water to remove the excess guest ( $c a .25 \mathrm{~mL}, 5 \mathrm{~mL} / \mathrm{min}$ ). The column was washed with $\mathrm{D}_{2} \mathrm{O}(5 \mathrm{~mL}, 5 \mathrm{~mL} / \mathrm{min})$ and then eluted with $\mathrm{D}_{2} \mathrm{O}(3 \times 1 \mathrm{~mL}, 1 \mathrm{~mL} / \mathrm{min})$ and then aqueous DCM $(3 \times 1 \mathrm{~mL}, 1 \mathrm{~mL} / \mathrm{min})$. The final $\mathrm{D}_{2} \mathrm{O}$ elution and all aqueous DCM elutions were analyzed by ${ }^{1} \mathrm{H} \mathrm{NMR}$.

\section{Diels-Alder Experiments}

Acidic alumina ( $c a .340 \mathrm{mg}$ ) was added to a solution of excess 1 in HPLC water $(3.3 \mathrm{~mL})$ and stirred. Basic alumina (ca. $1 \mathrm{~g}$ ) was added to a solution of excess 2 in HPLC water $(10 \mathrm{~mL})$ and stirred. The two alumina slurries were loaded into separate $3 \mathrm{~mL}$ syringes with cotton 
wool plugs and washed with HPLC water to remove the excess cage. The cage column of $\mathbf{1}$ was eluted with aqueous cyclopentadiene (ca. $20 \mathrm{mM}, 3 \mathrm{~mL}, 0.1 \mathrm{~mL} / \mathrm{min})$ and washed with

HPLC water ( $c a .25 \mathrm{~mL}$ ). The cage column of 2 was eluted with aqueous N-propyl maleimide (ca. $20 \mathrm{mM}, 3 \mathrm{~mL}, 0.1 \mathrm{~mL} / \mathrm{min}$ ) and washed with HPLC water $(c a .25 \mathrm{~mL})$. The two cage columns were then stacked vertically, connected (see Figure 4) and washed with $\mathrm{D}_{2} \mathrm{O}(10$ $\mathrm{mL})$. Finally, the stacked system was eluted with $\mathrm{D}_{2} \mathrm{O}(3 \times 1 \mathrm{~mL}, 1 \mathrm{~mL} / \mathrm{min})$ and then aqueous DCM (saturated, $6 \times 1 \mathrm{~mL}, 1 \mathrm{~mL} / \mathrm{min}$ ). The final $\mathrm{D}_{2} \mathrm{O}$ elution and all aqueous DCM elutions were analyzed by ${ }^{1} \mathrm{H}$ NMR.

\section{Supporting Information}

Supporting Information is available from the Wiley Online Library or from the author.

\section{Acknowledgements}

H.P.R., C.J.E.H., and A.B.G. acknowledge support from the UK Engineering and Physical Sciences Research Council (EPSRC EP/P027067/1) and the European Research Council (ERC 695009). H.P.R. acknowledges funding from the Cambridge Commonwealth, European and International Trust and Christ's College, University of Cambridge. A.S. acknowledges funding from the Biotechnology and Biological Sciences Research Council (BB/M011194/1). Additionally, the authors would like to thank the NMR facility, the Vignolini Bio-Inspired Photonics Group at the Department of Chemistry, and Dr Heather Greer, University of Cambridge.

\section{References}

1] D. Zhang, T. K. Ronson, J. R. Nitschke, Accounts of Chemical Research 2018, 51, 2423.

[2] R. Chakrabarty, P. S. Mukherjee, P. J. Stang, Chemical Reviews 2011, 111, 6810.

[3] Q. Shi, X. Zhou, W. Yuan, X. Su, A. Neniškis, X. Wei, L. Taujenis, G. Snarskis, J. S. Ward, K. Rissanen, J. de Mendoza, E. Orentas, Journal of the American Chemical Society 2020, $142,3658$.

[4] Q. Zhang, L. Catti, K. Tiefenbacher, Accounts of Chemical Research 2018, 51, 2107. 
[5] R. D. Mukhopadhyay, Y. Kim, J. Koo, K. Kim, Accounts of Chemical Research 2018, 51, 2730.

[6] D. P. August, G. S. Nichol, P. J. Lusby, Angewandte Chemie International Edition 2016, 55, 15022.

[7] W. Wang, Y. X. Wang, H. B. Yang, Chemical Society Reviews 2016, 45, 2656.

[8] M. C. Young, L. R. Holloway, A. M. Johnson, R. J. Hooley, Angewandte Chemie International Edition 2014, 53, 9832.

[9] F. J. Rizzuto, L. K. S. von Krbek, J. R. Nitschke, Nature Reviews Chemistry 2019, 3, 204.

[10] F. K.-W. Kong, A. K.-W. Chan, M. Ng, K.-H. Low, V. W.-W. Yam, Angewandte Chemie International Edition 2017, 56, 15103.

[11] L. J. Wang, X. Li, S. Bai, Y. Y. Wang, Y. F. Han, Journal of the American Chemical Society 2020, 142, 2524.

[12] K. Niki, T. Tsutsui, M. Yamashina, M. Akita, M. Yoshizawa, Angewandte Chemie International Edition 2020, DOI 10.1002/anie.202003253.

[13] D. Luo, M. Li, X.-P. Zhou, D. Li, Chemistry - A European Journal 2018, 24, 7108.

[14] H. Löw, E. Mena-Osteritz, K. M. Mullen, C. M. Jäger, M. Delius, ChemPlusChem 2020, 85,1008 .

[15] M. E. Carnes, M. S. Collins, D. W. Johnson, Chemical Society Reviews 2014, 43, 1825.

[16] M. A. Little, A. I. Cooper, Advanced Functional Materials 2020, 1909842.

[17] H. L. Ozores, M. Amorín, J. R. Granja, Journal of the American Chemical Society 2017, $139,776$.

[18] P. Mal, B. Breiner, K. Rissanen, J. R. Nitschke, Science 2009, 324, 1697.

[19] A. Galan, P. Ballester, Chemical Society Reviews 2016, 45, 1720.

[20] M. Kieffer, A. M. Garcia, C. J. E. Haynes, S. Kralj, D. Iglesias, J. R. Nitschke, S. Marchesan, Angewandte Chemie International Edition 2019, 58, 7982.

[21] D. Zhang, T. K. Ronson, J. Mosquera, A. Martinez, J. R. Nitschke, Angewandte Chemie International Edition 2018, 57, 3717.

[22] A. B. Grommet, J. B. Hoffman, E. G. Percástegui, J. Mosquera, D. J. Howe, J. L. Bolliger, J. R. Nitschke, Journal of the American Chemical Society 2018, 140, 14770.

[23] B.-N. T. Nguyen, A. B. Grommet, A. Tron, M. C. A. Georges, J. R. Nitschke, Advanced Materials 2020, 32, 1907241.

[24] C. Tan, D. Chu, X. Tang, Y. Liu, W. Xuan, Y. Cui, Chemistry - A European Journal 2019, 25,662 .

[25] Y. Fang, J. A. Powell, E. Li, Q. Wang, Z. Perry, A. Kirchon, X. Yang, Z. Xiao, C. Zhu, L. Zhang, F. Huang, H. C. Zhou, Chemical Society Reviews 2019, 48, 4707.

[26] M. D. Ward, C. A. Hunter, N. H. Williams, Accounts of Chemical Research 2018, 51, 2073.

[27] C. M. Hong, R. G. Bergman, K. N. Raymond, F. D. Toste, Accounts of Chemical Research 2018, 51, 2447.

[28] D. Preston, J. J. Sutton, K. C. Gordon, J. D. Crowley, Angewandte Chemie International Edition 2018, 57, 8659.

[29] M. Yoshizawa, M. Tamura, M. Fujita, Science 2006, 312, 251.

[30] A. B. Grommet, M. Feller, R. Klajn, Nature Nanotechnology 2020, 15, 256.

[31] K. Wang, J. H. Jordan, X. Hu, L. Wang, Angewandte Chemie International Edition 2020, anie. 202000045.

[32] J. M. Palomo, RSC Advances 2014, 4, 32658.

[33] S. Zaramella, E. Yeheskiely, R. Strömberg, Journal of the American Chemical Society 2004, 126, 14029.

[34] N. Malik, N. Elool Dov, G. de Ruiter, M. Lahav, M. E. van der Boom, ACS Applied Materials and Interfaces 2019, 11, 22858.

[35] M. Lahav, M. E. van der Boom, Advanced Materials 2018, 30, 1706641. 
[36] Y. Atoini, E. A. Prasetyanto, P. Chen, S. Silvestrini, J. Harrowfield, L. De Cola, Chemistry - A European Journal 2018, 24, 12054.

[37] S. Carrara, A. Aliprandi, C. F. Hogan, L. de Cola, Journal of the American Chemical Society 2017, 139, 14605.

[38] W. Li, A. T. Bockus, B. Vinciguerra, L. Isaacs, A. R. Urbach, Chemical Communications 2016, 52, 8537.

[39] A. Fernando, T. L. Mako, A. M. Levenson, P. T. Cesana, A. M. Mendieta, J. M. Racicot, B. DeBoef, M. Levine, Supramolecular Chemistry 2019, 31, 545.

[40] W. Liu, S. K. Samanta, B. D. Smith, L. Isaacs, Chemical Society Reviews 2017, 46, 2391.

[41] W. Liu, C. F. A. Gómez-Durán, B. D. Smith, Journal of the American Chemical Society 2017, 139, 6390 .

[42] M. Busi, M. Laurenti, G. G. Condorelli, A. Motta, M. Favazza, I. L. Fragalà, M. Montalti, L. Prodi, E. Dalcanale, Chemistry - A European Journal 2007, 13, 6891.

[43] S. A. Levi, P. Guatteri, F. C. J. M. van Veggel, G. J. Vancso, E. Dalcanale, D. N. Reinhoudt, Angewandte Chemie International Edition 2001, 40, 1892.

[44] E. Menozzi, R. Pinalli, E. A. Speets, B. J. Ravoo, E. Dalcanale, D. N. Reinhoudt, Chemistry - A European Journal 2004, 10, 2199.

[45] S. Eslava, A. C. Papageorgiou, S. K. Beaumont, G. Kyriakou, D. S. Wright, R. M. Lambert, Chemistry of Materials 2010, 22, 5174.

[46] S. Mekapothula, M. A. Addicoat, D. J. Boocock, P. Cragg, J. D. Wallis, G. W. V. Cave, Chemical Communications 2020, 56, 1792.

[47] Q.-H. Yuan, L.-J. Wan, A. Hershel Jude, Peter J. Stang, Journal of the American Chemical Society 2005, 127, 16279.

[48] M. Frank, S. Funke, H. Wackerbarth, G. H. Clever, Physical Chemistry Chemical Physics 2014, 16, 21930.

[49] J. L. Bolliger, T. K. Ronson, M. Ogawa, J. R. Nitschke, Journal of the American Chemical Society 2014, 136, 14545.

[50] D. Schultz, J. R. Nitschke, Angewandte Chemie International Edition 2006, 45, 2453.

[51] P. Mal, D. Schultz, K. Beyeh, K. Rissanen, J. R. Nitschke, Angewandte Chemie International Edition 2008, 47, 8297.

[52] A. Ebadi, J. S. Soltan Mohammadzadeh, A. Khudiev, Adsorption 2009, 15, 65.

[53] G. Blanchard, M. Maunaye, G. Martin, Water Research 1984, 18, 1501.

[54] M. M. J. Smulders, S. Zarra, J. R. Nitschke, Journal of the American Chemical Society 2013, 135, 7039 .

[55] M. H. Abraham, J. Le, Journal of Pharmaceutical Sciences 1999, 88, 868.

[56] F. J. Rizzuto, J. P. Carpenter, J. R. Nitschke, Journal of the American Chemical Society 2019, 141, 9087. 